\title{
Cryoablation combined with allogenic natural killer cell immunotherapy improves the curative effect in patients with advanced hepatocellular cancer
}

\author{
Mao Lin ${ }^{1,2}$, Shuzhen Liang ${ }^{1}$, Xiaohua Wang ${ }^{1}$, Yinqing Liang ${ }^{1}$, Mingjie Zhang ${ }^{3}$, Jibing \\ Chen ${ }^{1,2}$, Lizhi $\mathrm{Niu}^{1,2,4}$ and Kecheng $\mathrm{X} \mathbf{u}^{1,2}$ \\ ${ }^{1}$ Department of Biological Treatment Center, Fuda Cancer Hospital, Jinan University School of Medicine, Guangzhou, China \\ ${ }^{2}$ Fuda Cancer Institute, Guangzhou, China \\ ${ }^{3}$ Hank Bioengineering Co., Ltd., Shenzhen, China \\ ${ }^{4}$ Department of Oncology, Fuda Cancer Hospital, Jinan University School of Medicine, Guangzhou, China \\ Correspondence to: Lizhi Niu, email: 18922210657@163.com \\ Jibing Chen, email: linmaogz@163.com
}

Keywords: curative effect, percutaneous cryoablation, allogenic natural killer cell, hepatocellular cancer, progression-free survival

Received: April 07, 2017

Accepted: April 29, 2017

Published: May 11, 2017

Copyright: Lin et al. This is an open-access article distributed under the terms of the Creative Commons Attribution License 3.0 (CC BY 3.0), which permits unrestricted use, distribution, and reproduction in any medium, provided the original author and source are credited.

\section{ABSTRACT}

In this study, the clinical efficacy of cryosurgery combined with allogenic natural killer cell immunotherapy for advanced hepatocellular cancer was evaluated. From October 2015 to March 2017, we enrolled 61 patients who met the enrollment criteria and divided them into two groups: 1) the simple cryoablation group (Cryo group, $n=26$ ); and 2 ) the cryoablation combined with allogenic natural killer cells group (Cryo-NK group, $n=35$ ), the safety and short-term effects were evaluated firstly, then the median progression-free survival, response rate and disease control rate were assessed. All adverse events experienced by the patients were recorded, and included local (e.g., pain, pleural effusion, and ascites) and systemic (e.g., chills, fatigue, and fever) reactions, fever was more frequent. Other possible seriously side effects (e.g., blood or bone marrow changes) were not detected. Combining allogeneic natural killer cells with cryoablation had a synergistic effect, not only enhancing the immune function, improving the quality of life of the patients, but also reducing the expression of AFP and significantly exhibiting good clinical efficacy of the patients. After a median follow-up of 8.7 months (3.9 -15.1months), median progressionfree survival was higher in Cryo-NK (9.1 months) than in Cryo (7.6 months, $P=0.0107)$, median progression-free survival who received multiple natural killer was higher than who just received single natural killer (9.7 months vs.8.4 months, $P=0.0011$, respectively), the response rate in Cryo-NK $(60.0 \%)$ was higher than in Cryo $(46.1 \%, P<0.05)$, the disease control rate in Cryo-NK $(85.7 \%)$ was higher than in Cryo group $(69.2 \%, P<0.01)$. Percutaneous cryoablation combined with allogeneic natural killer cell immunotherapy significantly increased median progression-free survival of advanced hepatocellular cancer patients. Multiple allogeneic natural killer cells infusion was associated with better prognosis to advanced hepatocellular cancer.

\section{INTRODUCTION}

Hepatocellular carcinoma (HCC), which is the most common type of primary liver cancer, due to usually discovered late and has a poor prognosis [1]. Although surgical resection is the best option to HCC, but many patients suffer bad factors such as cirrhosis, multiple tumors or other diseases, so they are unsuitable for surgical 
resection [2, 3]. Up to now, systemic chemotherapy dose not obviously increase survival advanced HCC patients $[4,5]$. Radiation has toxicity to the normal liver, so it is limited method to treat HCC $[6,7]$. Hence, the newer and more effective therapies for advanced HCC patients are needed.

Percutaneous cryoablation is a new method which can induce tumor necrosis, it is currently considered the best option for treating unresectable HCC [8]. Cryosurgery has many advantages which carried out successfully in many solid tumors (e.g., prostate cancer and RR) [9, 10], and also emerged as a new therapy pattern for $\operatorname{HCC}[11,12]$.

There are some reports have stated that cancer occurence and development in HCC patients are affected by the tumor immune [13-18]. However, due to downregulating the expression of $\mathrm{MHC}$, tumor cells often immune escape [19]. Manipulating the immune system for therapeutic benefit in HCC patients has been studied for many decades [20-22]. NK cells are belonged to the innate immune system and play a importment role against cancer in the early time $[23,24]$. With progress in the NK cell biology field and in understanding NK function, adoptive NK cell transfer has promising anti-tumor effects on various cancers [25-29], including liver cancer [30-34].

In our research, we prospectively investigated the clinical response of cryosurgery combining with NK cell immunology for advanced HCC, to elucidate a potential therapeutic strategy.

\section{RESULTS}

\section{Identification of $\mathrm{NK}$ cells in the enrolled patients}

In line with the protocol described in Figure 1B, the peripheral blood of the enrolled patients' kinsfolk was separated in the laboratory. Prior to the cell culture, the median fraction of the $\mathrm{CD} 3{ }^{-} \mathrm{CD} 56^{+}$population was $6.69 \%$ (range: $4.3 \%-14.9 \%$ ). Following the cell culture and expansion, the viable cells exceed $90 \%$. The median proportion of CD56+ cells was $86.1 \%$ (range: $71.6 \%$ - 96.1\%). The median percentage, viable cells and the median proportion of CD56+CD3- cells were similar to our prior report [35]. The representative results are presented in Figure 2.

\section{Patient demographics}

61 patients come around the world, China $(n=31)$, Indonesia $(n=11)$, Malaysia $(n=12)$ and Mid East $(n=7)$. The data were no statistical differences (Table $1, P>0.05$ ).

\section{Safety and clinical efficacy evaluation}

All adverse events were recorded, including local (e.g., pain, pleural effusion, and ascites) and systemic (e.g., chills, fatigue, and fever) reactions, fever was more frequent.
The adverse events was compared using a chi-square test; they were no differences $(P=0.8481$; Figure $3 \mathrm{~A})$.

The pre-treatment immune test data of were merged and compared with post-treatment (Table 2). Aimed to the counts, all cells were exceed in the Cryo-NK group following treatment $(P<0.01)$, especially to NK, the number in Cryo-NK group was significantly higher $(P<0.001)$. Considering lymphocyte functionality, the level of Th1 cytokines was also improved in the cryoNK group, the level of Th2 cytokine levels remained invariability.

AFP expression was higher than normal at 1 day pre-treatment and decreased gradually at day 3 , and 1 month and 3 months post-treatment in the two groups (Figure 3B). There was no difference between the two groups at post-treatment day $3(P>0.05)$, but at 1 month and 3 months post-treatment, AFP expression was obviously lower in the Cryo-NK (Figure 3B, $P<0.01$ ), even there were 13 patients within normal range who received Cryo-NK therapy.

The pre-treatment KPS of the Cryo- and Cryo-NK groups was $68.7 \pm 6.5$ and $70.1 \pm 3.7$, respectively, $78.6 \pm$ 4.2 and $82.9 \pm 5.1$ one month post-treatment, respectively, and $81.2 \pm 4.7$ and $90.1 \pm 1.6$ at three months posttreatment, respectively. Compared with the pre-treatment KPS, the scores of both groups were obviously improved post-treatment (Figure 3C; $P<0.01$ ); however, the KPS was higher in the Cryo-NK group both one month and three months post-treatment (Figure 3D; $P<0.05$ ).

The clinical efficacy between the two groups was observed three months post-treatment. The maximum transverse diameters are listed in Table 3. The tumor volume was obviously decreased post-treatment in both two groups; however, three months post-treatment, the maximum tumor diameter in cryo-NK was smaller than Cryo $(P<0.01)$. In Table 4 , CT value was obviously decreased post-treatment, the CT value three months posttreatment in the Cryo-NK group was lower than that of the Cryo group $(P<0.05)$. During the follow-up period, there was no patient died; the number of CR in Cryo was 5 but 9 in cryo-NK (Table 5). In addition, the RR in cryo-NK was $60.0 \%$ higher than $46.1 \%$ in Cryo $(P<0.01)$, similarly, DCR in cryo-NK was obviously higher than patients who just received Cryo ( $85.2 \%$ vs. $69.5 \%, P<0.01)$. The representative results are shown in Figure 4.

After a median follow-up of 8.7 months (3.1 -14.3months), median PFS was higher in Cryo-NK (9.1 months) than in Cryo group (7.6 months, $P=0.0107$, Figure 5A), median PFS who received multiple NK was higher than who just received single NK (9.6 vs.8.4 months, $P=0.0011$, respectively, Figure 5B).

\section{DISCUSSION}

For the majority of patients with advanced HCC, tumor is not suitable to resect. With many advances and 
Table 1: Patient demographics

\begin{tabular}{lccc}
\hline \multicolumn{1}{c}{ Patient characteristics before treatment } & Cryoablation $(\boldsymbol{n}=\mathbf{2 6})$ & Cryo-NK $(\boldsymbol{n}=\mathbf{3 5})$ & $\boldsymbol{P}$ value \\
\hline Gender (Male/Female) & $14 / 12$ & $18 / 17$ & $P=0.824$ \\
Median age (y) & 56 & 61 & $P=0.715$ \\
Child-Pugh Stratification & 11 & & $P=0.763$ \\
Class A & 15 & 16 & \\
Class B & & & \\
Clinical stage (AJCC) & 12 & 17 & \\
III & 14 & 18 & \\
IV & & & \\
Karnofsky performance status & 13 & 14 & \\
70 & 8 & 15 & \\
80 & 5 & 6.744 \\
90 & 12 & 14 & \\
Hepatitis B/C+ & 23 & 22 & $P=0.836$ \\
TACE & & & \\
\hline
\end{tabular}

AJCC, American Joint Committee on Cancer staging system; TACE, Transarterial chemoembolization.

Table 2: Comparison of the number and function of lymphocytes

\begin{tabular}{lccc}
\hline \multicolumn{1}{c}{ Test items of lymphocyte } & \multicolumn{3}{c}{ Test results } \\
\cline { 2 - 4 } & Pre-treatment $(\boldsymbol{n}=\mathbf{6 1})$ & Cryoablation $(\boldsymbol{n}=\mathbf{2 6})$ & Cryo-NK $(\boldsymbol{n}=\mathbf{3 5})$ \\
\hline Number $(\mathrm{cell} / \mu \mathrm{L}):$ & & \\
Total T cell & $1456 \pm 52$ & $1623 \pm 67^{*}$ & $1812 \pm 91^{* * *}$ \\
CD8+T cell & $621 \pm 7$ & $727 \pm 29^{*}$ & $754 \pm 11^{* *}$ \\
CD4+T cell & $735 \pm 30$ & $821 \pm 35^{*}$ & $856 \pm 33^{* *}$ \\
NK cell & $372 \pm 31$ & $552 \pm 63^{*}$ & $786 \pm 73^{* * *}$ \\
B cell & $309 \pm 11$ & $465 \pm 33^{* *}$ & $551 \pm 41^{*}$ \\
Function $(\mathrm{pg} / \mathrm{mL}):$ & & \\
IL-2 & & $17.6 \pm 3.5^{* *}$ & $23 \pm 4.6^{* * *}$ \\
TNF- $\beta$ & $9.9 \pm 3.4$ & $9.8 \pm 2.5^{* * *}$ & $14 \pm 2.5^{* * *}$ \\
IFN- $\gamma$ & $3.8 \pm 2.2$ & $10.8 \pm 3.6^{* *}$ & $16 \pm 37^{* * *}$ \\
IL-4 & $4.8 \pm 3.3$ & $10.1 \pm 3.4$ & $11.2 \pm 3.6$ \\
IL-6 & $10.2 \pm 2.1$ & $15.2 \pm 4.5$ & $15.5 \pm 7.9^{* *}$ \\
IL-10 & $13.2 \pm 3.9$ & $9.3 \pm 2.3$ & $10.1 \pm 3.4$ \\
\hline
\end{tabular}

Note: All cell subsets and cytokines were analyzed via a Dunnett's multiple comparison test (one-way ANOVA). NK cell, natural killer cell; IL, interleukin; TNF, tumor necrosis factor; IFN, interferon ${ }^{*} P<0.05 ; * * P<0.01 ; * * * P<0.001$.

Table 3: The maximum transverse diameter of the lesions pre- and post-treatment

\begin{tabular}{lccc}
\hline \multicolumn{1}{c}{ Time } & \multicolumn{1}{c}{ Maximum diameter $(\mathbf{m m})$} & \multicolumn{1}{c}{$\boldsymbol{P}$ value } \\
\cline { 2 - 4 } & Cryoablation & Cryo-NK & $P>0.05$ \\
Pre-treatment & $4.68 \pm 3.13$ & $4.59 \pm 3.38$ & \\
1 month post-treatment & $4.12 \pm 3.00$ & $4.07 \pm 3.24$ & $P>0.05$ \\
3 months post-treatment & $4.04 \pm 3.01$ & $3.68 \pm 2.46$ & $P<0.05$ \\
\hline
\end{tabular}


Table 4: The CT value of lesions pre- and post- treatment

\begin{tabular}{lccc}
\hline \multicolumn{1}{c}{ Time } & \multicolumn{1}{c}{ Plain CT value (Hu) } & P value \\
\cline { 2 - 3 } & Cryoablation & Cryo-NK & $P>0.05$ \\
\hline Pre-treatment & $43.01 \pm 7.66$ & $42.29 \pm 7.12$ & $P>0.05$ \\
1 month post-treatment & $25.58 \pm 2.06$ & $24.87 \pm 3.12$ & $P<0.05$ \\
3 months post-treatment & $24.87 \pm 3.25$ & $23.21 \pm 3.68$ & \\
\hline
\end{tabular}

A
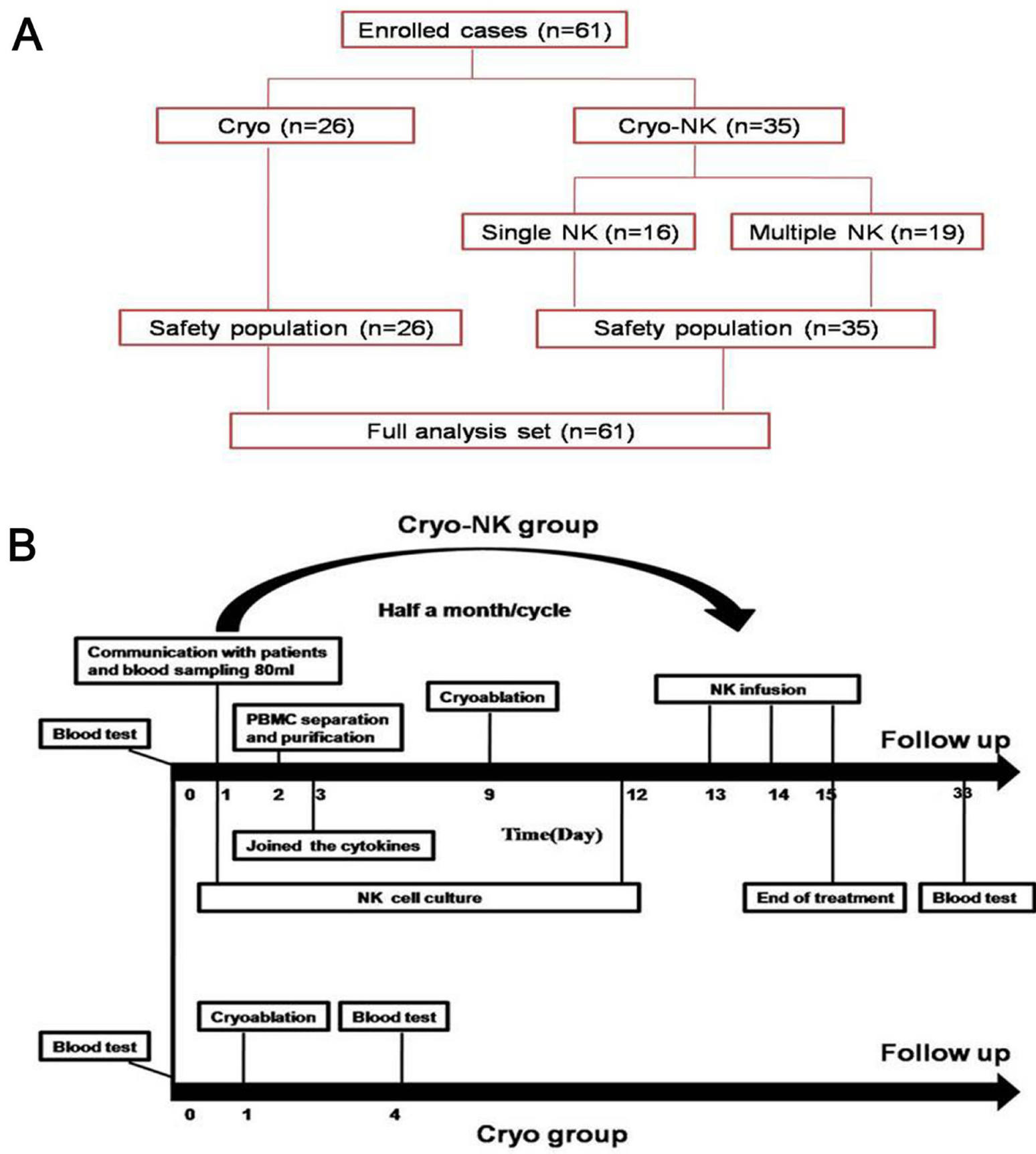

Figure 1: (A) The enrolled patients were allocated to cryoablation group $(n=26)$ and Cryo-NK group $(n=35,16$ patients underwent one course NK and 19 patients underwent $\geq 3$ courses). (B) The treatment schedule. All of the enrolled patients' kinsfolk were informed, and the peripheral blood was collected for isolation of NK cells seven days before cryoablation, cryoablation was carried out on Day 9 and Day 12 , the cultured NK cells were intravenously infused on days 13 to 15 , while only cryoablation was performed in the cryotherapy group. 
Table 5: Clinical response between the two groups at three months post-treatment

\begin{tabular}{lcccc}
\hline & Total & Cryo & Cryo-NK & $P$ value \\
\hline Number & 61 & 26 & 35 & $P>0.05$ \\
CR & 13 & 5 & 9 & $P>0.05$ \\
PR & 19 & 7 & 12 & $P<0.05$ \\
SD & 15 & 6 & 9 & $P>0.05$ \\
PD & 14 & 8 & 5 & $P>0.05$ \\
RR (\%) & 52.4 & 46.1 & 60.0 & $P<0.05$ \\
DCR (\%) & 77.1 & 69.2 & 85.7 & $P<0.01$ \\
\hline
\end{tabular}

Clinical responses were evaluated according to Response Evaluation Criteria in Solid Tumors version 1.1. CR, complete response; PR, partial response; $\mathrm{SD}$, stable disease; $\mathrm{PD}$, progressive disease; RR, response rate; $\mathrm{DCR}$, disease control rate.

imaging, cryoablation becomes successfully for treating HCC [36-38]. Ar-He cryoablation is a novel microinvasive treatment of tumor, which tumors are frozen and then left in situ to be reabsorbed. Cryoablation is a development technology with minimally invasive treatment of tumor in recent years, can quickly damage to tumor tissue, reduce tumor load. In this study, cryoablation was showed a safety and efficacy to advanced HCC patients for short term observation. However, due to the vast majority of advanced HCC patients have been confirmed the existence of the distal metastasis, cryoablation only treat primary tumors or metastases, possible role limited for advanced HCC cell metastasis.

It is increasingly clear that cancer occurence and development in HCC patients are affected by tumor immune $[39,40]$. The recent success of immunotherapy has highlighted the potential of immune-based therapy approaches for advanced HCC treatment [21, 41, 42]. Our previous research of Cryo-DC/CIK treatment with

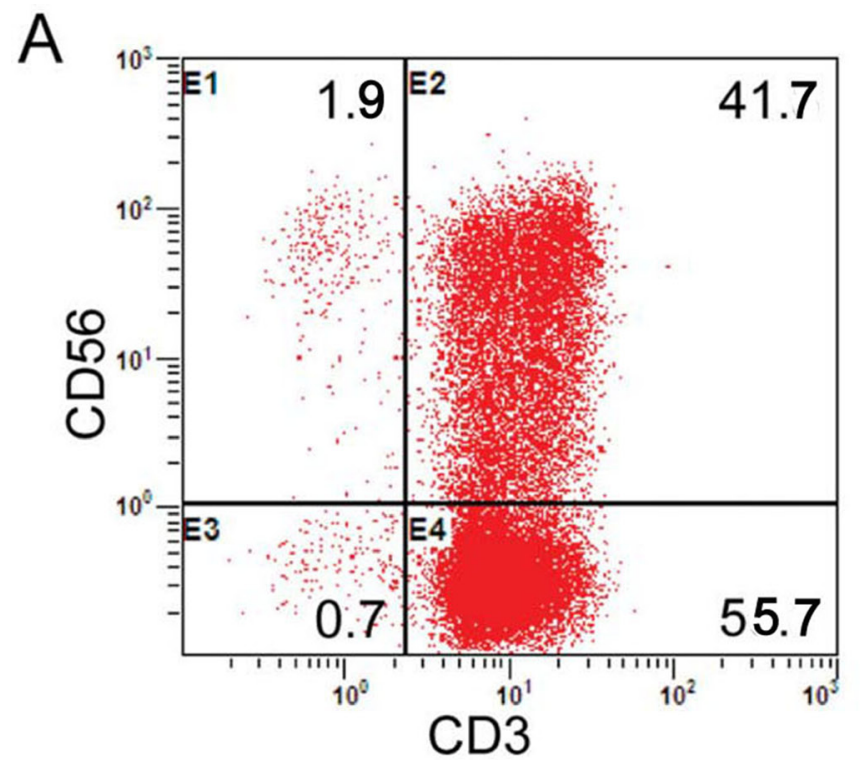

in metastatic pancreatic cancer [43] and HCC [44] has displayed a good clinical outcome. After cryoablation, account of continued antigen released, which could stimulate the immune system sequentially, but CIK could not kill the low tumor burden directly, so we brought in NK cells technology by understanding NK function. In our study, we attempted to investigate the safety and clinical efficacy of percutaneous cryoablation combined with allogeneic natural killer cell therapy for treating advanced HCC, then the median PFS, RR and DCR were assessed. To our surprise was that allogeneic NK cells combined with cryosurgical for advanced HCC exhibited a synergistic effect, significantly enhanced the immune function of patients (Table 2). The increasing number of NK cells after allogeneic NK cells immunotherapy may be related to ectogenic NK cells amplified, because NK cells were infused in the period of logarithmic phase which owned the best activity and amplified sequentially. Moreover, combined treatment can markedly improve the

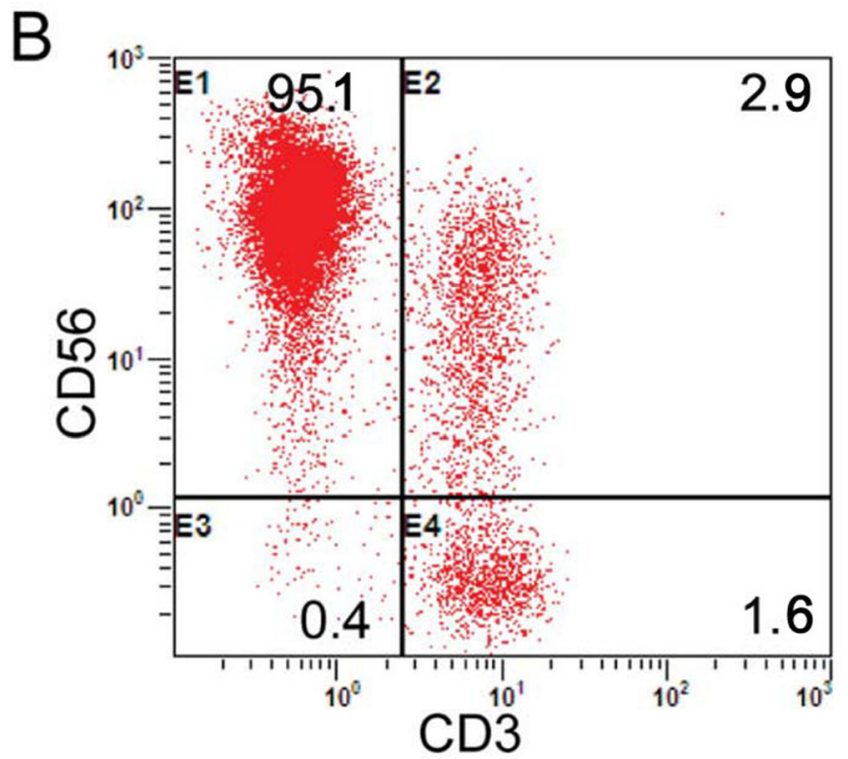

Figure 2: Proportion analysis of CD3-CD56+ cells (NK cells). (A) The proportion of NK cells before the expansion; (B) The proportion of NK cells after expansion on Day 9. 
median PFS prolonger, and the median PFS was higher in patients who received multiple NK than who just underwent only one course NK, also to RR and DCR (both $P<0.05)$. Facts proved that this comprehensive therapy was also safety and efficacy.

For decades, natural killer (NK) NK cells existed as "non-specific" killer cells were different from CTL or other immunocytes identified the target. We have learned that NK cells are trained to recognize "non-self" histocompatibility antigens (human leukocyte antigen, HLA) on the surface of cells through their killer cell immunoglobulin-like (KIR) receptors. Recent discoveries that better explain how $\mathrm{NK}$ cells recognize and kill their targets and their ability to produce immune-active cytokines have made them more attractive tools for immunotherapy. In view of this, we brought NK cells into this clinical research. In our previous report [45], showed a good outcome for allogenic NK cell immunotherapy to advanced renal cell cancer and metastasis pancreatic cancer [35]. Therefore, we used allogeneic NK cell adoptive therapy in this study. Facts proved that it was tolerant and efficacy. But whether the current number and purity of NK cells would be the optimal dose or not which is worthy us considering, maybe, we will carry out the dose grope in the future.

In conclusion, in this single-center prospective study, we provided evidence that allogeneic NK cell therapy combined with percutaneous cryoablation exhibited a favorable outcome for advanced HCC patients, indicating a potential novel therapeutic strategy.

\section{MATERIALS AND METHODS}

\section{Ethics}

This study was approved by the Ethics Committee of Guangzhou Fuda Cancer Hospital. In accordance with the Declaration of Helsinki, written informed consent
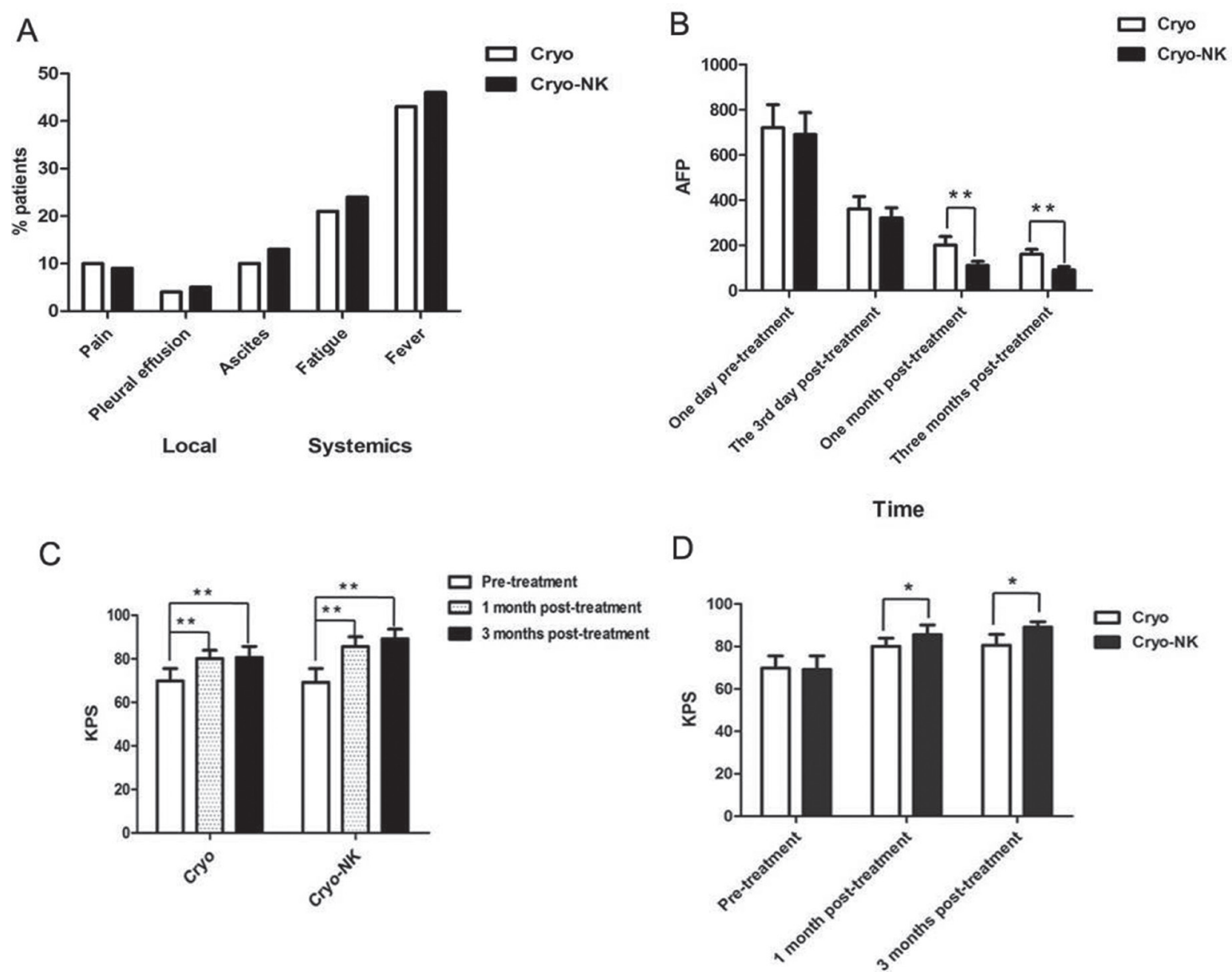

Figure 3: Safety and clinical efficacy evaluation. (A)Among the patients, the most common reactions included fever, pain, pleural effusion, and ascites were nearly remitted compared with the patients oral at pre-treatment following symptomatic treatment; (B) There was no difference between the two groups at post-treatment day $3(P>0.05)$, but at 1 month and 3 months post-treatment, AFP expression was obviously lower in the cryo-NK group than in the cryo group; $(\mathbf{C})$ Compared with the pre-treatment KPS, the scores of both groups were obviously improved post-treatment; (D) The KPS was higher in the cryo-NK group both one month and three months post-treatment. $* P<0.05 ; * * P<0.01$. 
A

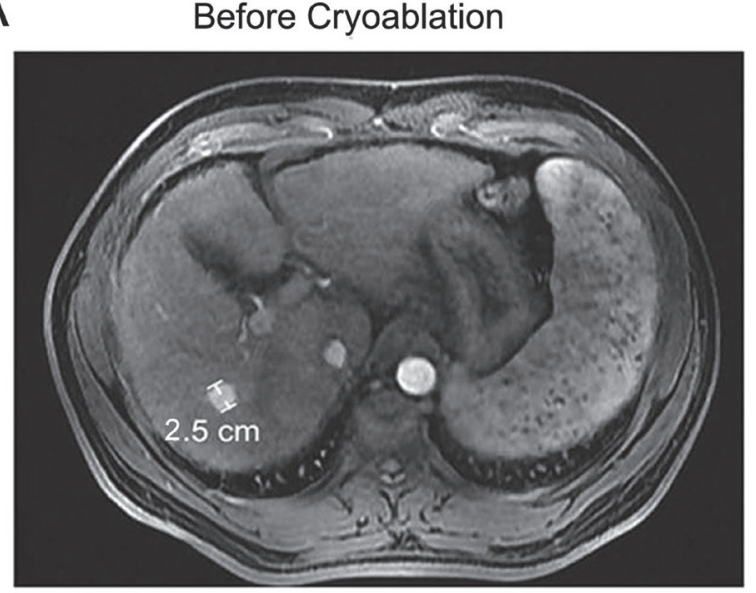

B

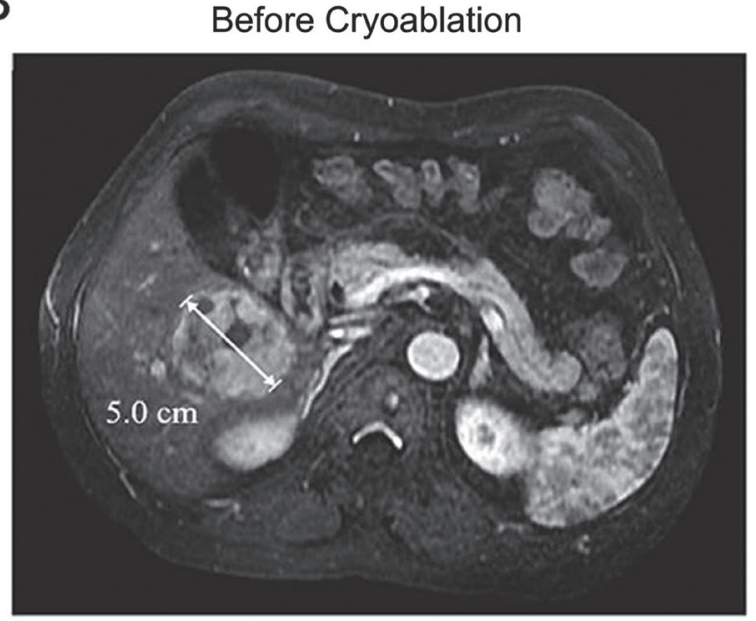

Three months post-Cryo-NK

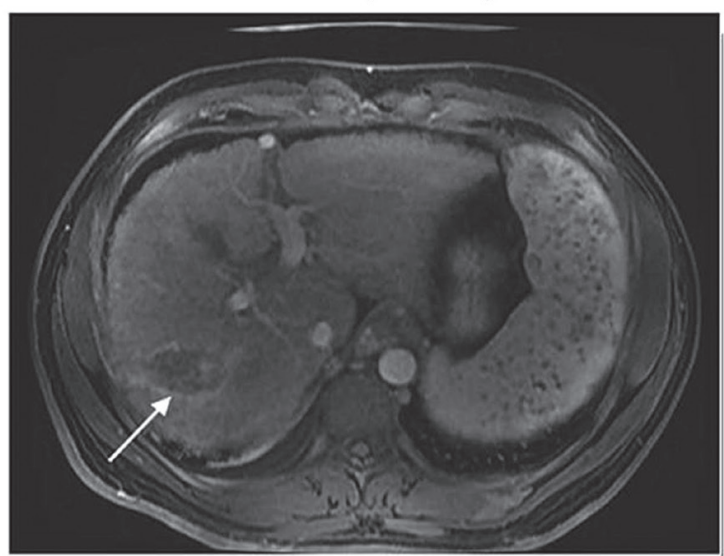

Three months post-Cryo-NK

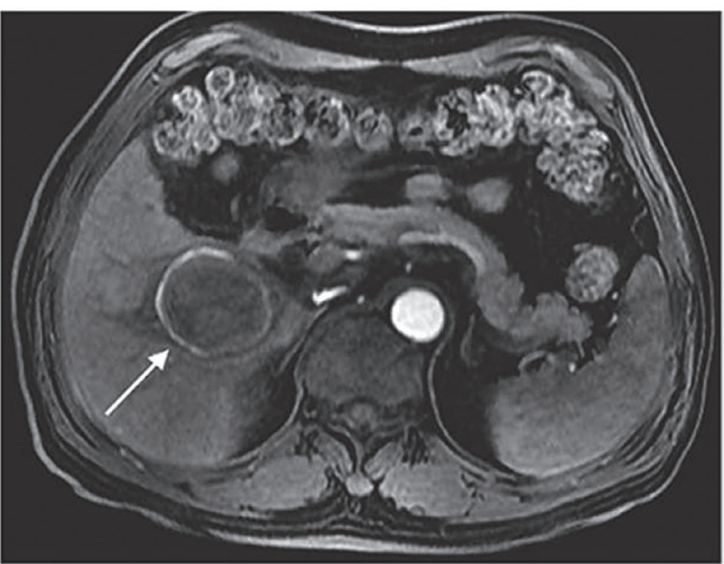

Figure 4: MRI images of 2 representative cases achieved CR at three months post-Cryo-NK. (A) Case \#1, a 50-year-old male, stage III, a maximum HCC nodule of $2.5 \mathrm{~cm}$, MRI showed no enhancement in the occupying lesion, with mild shrinkage of the area; (B) Case \#2, a 48-year-old female, stage IV, a maximum HCC nodule of $5.0 \mathrm{~cm}$, MRI showed a lesion with a large area of necrosis.
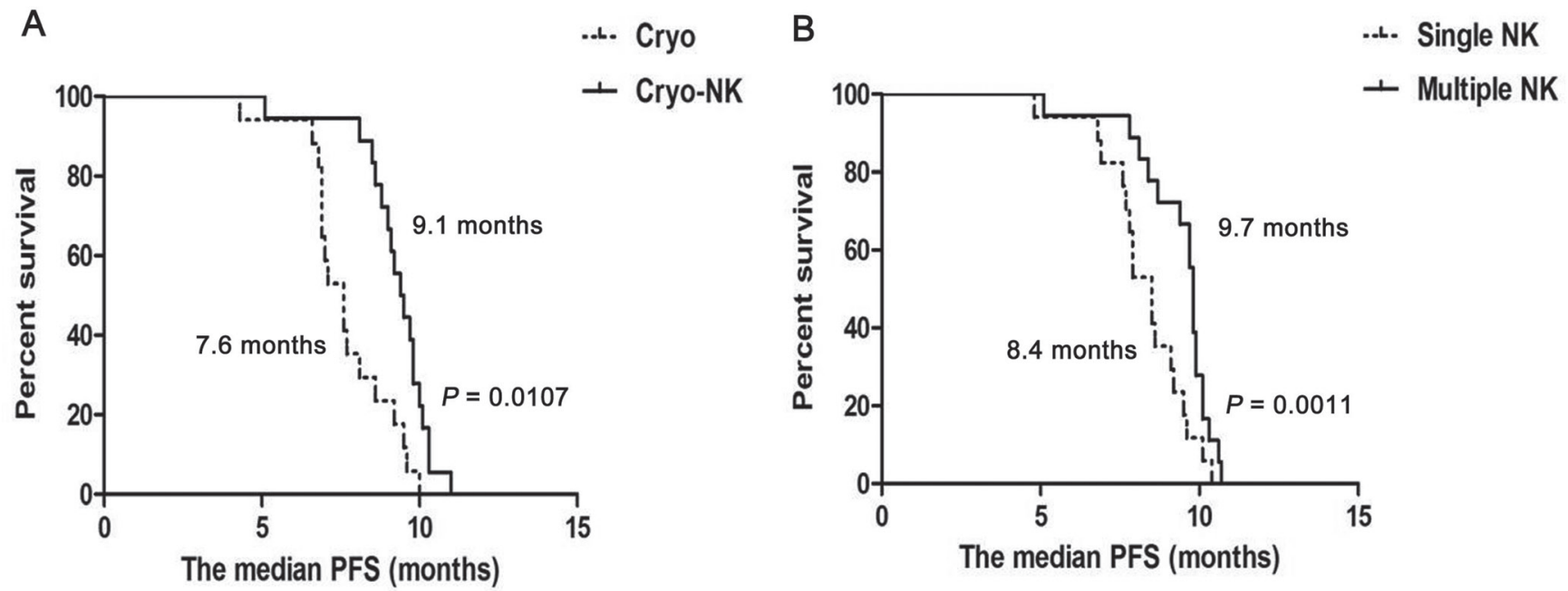

Figure 5: The median PFS from cryoablation. (A) The median PFS was higher in Cryo-NK (9.1 months) than in Cryo group (7.6 months, $P=0.0107)$; (B) The median PFS who received multiple NK was higher than who just received single NK (9.7 months vs.8.4 months, $P=0.0011$, respectively). 
was obtained from each participant at the Fuda Cancer Hospital.

\section{Patients}

This was a prospective study of the therapeutic effects of a combined treatment strategy on HCC patients enrolled from October 2015 to March 2017. We enrolled 61 patients using the following criteria: 1) expected survival $>$ three months; 2) aged between 20 to 80 years; 3) Karnofsky performance status $>70$; 4) the following parameters were normal: platelets $\geq 80 \times 10^{9} / \mathrm{L}$; white blood cells $\geq 3 \times 10^{9} / \mathrm{L}$; neutrophils $\geq 2 \times 10^{9} / \mathrm{L}$; hemoglobin $\geq 90 \mathrm{~g} / \mathrm{L}$; prothrombin time international normalized ratio, $0.8-1.5$; adequate hepatic function (bilirubin $<20 \mu \mathrm{M}$, aminotransferase $<60 \mathrm{U} / \mathrm{L}$ ) and renal function (serum creatinine $<130 \mu \mathrm{M}$, serum urea $<10 \mathrm{mM}$ ), 5) all patients had confirmed HCC by pathology; 6) the absence of level 3 hypertension, severe coronary disease, myelosuppression, respiratory disease, acute or chronic infection, and autoimmune diseases. The enrolled patients were allocated to Cryoablation group $(n=26)$ and Cryo-NK group $(n=35,16$ patients underwent one course NK and 19 patients underwent $\geq 3$ courses, Figure 1A) .

\section{Percutaneous cryoablation}

The percutaneous puncture point was determined by computed tomography (CT). All cryoablations were performed with the commercially available Cryocare Surgical System (Endocare, Irvine, CA, USA) using argon and helium gas as the cryogen. Cryoprobes $(3,5$ or $8 \mathrm{~mm})$ were inserted into the center of the tumor mass under CT guidance and two freeze/thaw cycles were performed, each reaching a temperature between $-125^{\circ} \mathrm{C}$ and $-150^{\circ} \mathrm{C}$ for $15 \mathrm{~min}$ followed by rewarming at $15-20^{\circ} \mathrm{C}$. A margin of at least $1 \mathrm{~cm}$ of normal breast tissue was frozen circumferentially around the tumor. For masses larger than $5 \mathrm{~cm}$ in diameter, two or three cryoprobes were placed within the center and periphery of the tumor, to ensure freezing of the entire mass. After cryoablation, antibiotics and haemostatic agents were administered and vital signs such as blood pressure, pulse, respiration and blood oxygen saturation were monitored routinely.

\section{CT and MRI examination}

HCC patients confirmed by pathology were required to undergo dynamic CT or MRI one week pre-treatment, with a follow-up at one and three months post-treatment. The maximum diameter and CT value were measured and compared between the pre- and post- treatment values. A comprehensive analysis combined with the clinical data was completed together by two experienced nuclear medicine physicians who had multiple years of experience in making CT diagnoses.

\section{NK cell therapy}

Clinical-grade NK cells were cultured using clinical-grade reagents and under good manufacturing practice conditions. The human high activity NK cell in vitro preparation kit was used (Hank Bioengineering Co. Ltd, Shenzhen, China) that contained chimeric active cellular factors on K562 cell membranes [46], plasma treatment fluid, lymphocyte culture fluid additives, serum-free medium additives and cell infusion additives. This kit is intended for expanding and activating NK cells in peripheral blood mononuclear cells in vitro to prepare NK cells of higher quantity, purity and activity, namely highly activated NK (HANK) cells [47]. Blood samples from the patient and donors were analyzed using the TIANamp Blood DNA kit (Tiangen Biotech Co., Ltd., Beijing, China) and KIR/HLA-C allotypes Genotyping Low Resolution kit (Tianjin Super Biotechnology Developing Co., Ltd., Tianjin, China). Approximately 8-10 billion HANK cells may be harvested after culture from $80 \mathrm{ml}$ of peripheral blood using NK cell serumfree medium and culture bags (Tianjin Haoyang Biological Manufacture Co., Ltd, Tianjin, China). Cell counting and quality control inspection are commonly performed on day 12 of culture, and the quality indicators include $\geq 8$ billion total cells with $\geq 90 \%$ living cells, $\geq 85 \%$ CD3-/CD56+ cells [47], $\leq 1 \mathrm{EU} / \mathrm{ml}$ endotoxin, $\geq 80 \%$ cell killing activity against K562 target cells [47], and bacteria-, fungi- and mycoplasma-negative culture. After 12 days of cell culture, the NK cells were divided into three groups and intravenously infused into the patients from Day 13 to 15. Each patient must two cycles NK therapy continuously as one course.

NK cells were generated according to previously published protocols [47], $80 \mathrm{ml}$ peripheral blood from allogenic donors was drawn 7 days before cryoablation and the immunotherapy was given 3 days after cryoablation.

For donor selection, the killer cell immunoglobulinlike receptors (KIRs) genotyping should be mismatched to the human leukocyte antigen (HLA) class I molecules of the patient [47-51]. We used PCR-SSP to detect the KIR/ HLA-Cw which can get the result on the day.

\section{Cryo-NK therapy procedure}

All of the enrolled patients' kinsfolk were informed, and the peripheral blood was collected for NK cell isolation seven days before cryoablation. Cryoablation was carried out on Day 9 and Day 12, and the cultured NK cells were infused intravenously from Days 13 to 15 (Figure 1B). 


\section{Safety and curative effect evaluation index}

\section{Adverse events}

The most common adverse reactions were recorded and included local (e.g., pain, pleural effusion, and ascites) and systemic (e.g., chills, fatigue, and fever) reactions.

\section{Detection of immune function}

$2 \mathrm{ml}$ peripheral blood from patients was drawn 1 day before cryoablation and 3 days after cryoablation or one course NK cells therapy (Figure 1B). BD Multitest 6-color TBNK Reagent (BD Biosciences, USA) was used to detect the number of $\mathrm{CD} 3+\mathrm{CD} 4+$ cells $(95 \%$ range: $441-2156$ cells $/ \mu 1), \mathrm{CD} 3+\mathrm{CD} 8+$ cells $(95 \%$ range: $125-$ 1312 cells $/ \mu \mathrm{l})$, total $\mathrm{CD} 3+$ cells $(95 \%$ range: $603-2990$ cells $/ \mu \mathrm{l}), \mathrm{CD} 3-\mathrm{CD} 19+$ cells (95\% range: $107-698$ cells/ $\mu \mathrm{l})$ and $\mathrm{CD} 3-\mathrm{CD} 16+\mathrm{CD} 56+$ cells (95\% range: 95-640 cells $/ \mu \mathrm{l})$. BD Cytometric Bead Array (CBA) Human Th1/ Th2 Cytokine Kit II (BD Biosciences, USA) was used to detect the expression levels of IL-2 (95\% range: 8-12.5 $\mathrm{pg} / \mathrm{ml})$, IL-4 (95\% range: $3.5-6 \mathrm{pg} / \mathrm{ml})$, IL-6 (95\% range: $2.7-8.5 \mathrm{pg} / \mathrm{ml}), \mathrm{IL}-10$ (95\% range: $1.8-4 \mathrm{pg} / \mathrm{ml})$, tumor necrosis factor (TNF; 95\% range: $1.7-2.5 \mathrm{pg} / \mathrm{ml}$ ) and IFN- $\gamma(95 \%$ range: $1.5-4 \mathrm{pg} / \mathrm{ml})$. The number and function of lymphocytes in the peripheral blood of patients were tested according to the protocols given in the instruction manuals. Results above or within the reference range were considered to indicate normal immune function. When one or more values were below the reference range, it was considered to indicate immune dysfunction.

\section{Quality of life (QOL)}

By karnofsky score standard as an index, after treatment, KPS increased $\geq 10$ divided into QOL improved, increased $<10$ divided into QOL stable, KPS reduced $\geq 10$ divided into QOL lower.

\section{AFP}

Using electrochemical luminescence immunity analyzer and accessory kit (Roche Cobase 411) to detect serum AFP concentration at 1 day pre-treatment and at day 3, 1 month, 3 months post-treatment, carried out in accordance with the instruments and reagents. AFP normal range: $0-20 \mathrm{ng} / \mathrm{ml}$.

\section{Imaging change}

The WHO first published the evaluation standards for the tumor curative effect for the main study objective of observing tumor changes [52]. According to the degree of change in the largest transverse diameter, the therapeutic effect is divided into a complete response (CR), partial response (PR), stable disease (SD), and progressive disease (PD). To accurately observe the therapeutic effects, the total area of all tumors before and after treatment was compared. The recent curative effect must be maintained for more than four weeks, and $\mathrm{CR}+\mathrm{PR}$ represented the effective rate (RR).

\section{Follow-up}

The patients were required to undergo plain $\mathrm{CT}$ and enhanced $\mathrm{CT}$ at 1 week pre-treatment, and followed at 1 month and 2 months post-treatment. Imaging procedures were conducted every 3 months thereafter. The endpoints of interest were progression-free survival (PFS). PFS was defined as the interval between Cryo and local relapse, distant metastasis, or death, whichever occurred first.

\section{Evaluation and statistical analysis}

Complications were recorded and classified in accordance with the Common Terminology Criteria of Adverse Events v4.0. Radiographic local tumor control was assessed using image-guided tumor ablation criteria [53]. The basic characteristics of the two groups were compared using the chi-square test; immunity detection result data are presented as the mean \pm standard deviation; the changes of imaging were compared using the Student's $t$-test; local and systemic adverse events were marked in the nursing records and compared using the Chi-square test. Significant differences were indicated by $P<0.05$, $P<0.01$ or $P<0.001$. All analyses were conducted using GraphPad software (GraphPad, San Diego, CA, USA).

\section{Abbreviations}

Hepatocellular cancer, HCC; natural killer, NK; progression-free survival, PFS; response rate, RR; disease control rate, DCR; major histo-compatibility complex, MHC; killer cell immunoglobulin-like receptors, KIRs.

\section{ACKNOWLEDGMENTS AND FUNDING}

We would like to thank the native English speaking scientists of Elixigen Company for editing our manuscript. This work was supported by the Science and Technology Program of Tianhe District, Guangzhou, China [grant number 201504KW008].

\section{CONFLICTS OF INTEREST}

The authors declare that there is no conflicts of interests.

\section{REFERENCES}

1. Said A, Wells J. Management of hepatocellular carcinoma. Minerva Med. 2009; 100:51-68.

2. Hodgson HJ. Primary hepatocellular carcinoma. Br J Hosp Med. 1983; 29:240, 6, 50 passim.

3. Dusheiko GM, Hobbs KE, Dick R, Burroughs AK. Treatment of small hepatocellular carcinomas. Lancet. 1992; 340:285-8.

4. Burroughs A, Hochhauser D, Meyer T. Systemic treatment and liver transplantation for hepatocellular carcinoma: two 
ends of the therapeutic spectrum. Lancet Oncol. 2004; 5:409-18.

5. Llovet JM, Ricci S, Mazzaferro V, Hilgard P, Gane E, Blanc JF, de Oliveira AC, Santoro A, Raoul JL, Forner A, Schwartz M, Porta C, Zeuzem S, et al. Sorafenib in advanced hepatocellular carcinoma. N Engl J Med. 2008; 359:378-90.

6. Davis CR. Interventional radiological treatment of hepatocellular carcinoma. Cancer Control. 2010; 17:87-99.

7. Fuss M, Salter BJ, Herman TS, Thomas CR Jr. External beam radiation therapy for hepatocellular carcinoma: potential of intensity-modulated and image-guided radiation therapy. Gastroenterology. 2004; 127:S206-17.

8. Bruix J, Sherman M. Management of hepatocellular carcinoma. Hepatology. 2005; 42:1208-36.

9. Kornprat P, Jarnagin WR, DeMatteo RP, Fong Y, Blumgart LH, D'Angelica M. Role of intraoperative thermoablation combined with resection in the treatment of hepatic metastasis from colorectal cancer. Arch Surg. 2007; 142:1087-92.

10. Levy D, Avallone A, Jones JS. Current state of urological cryosurgery: prostate and kidney. BJU Int. 2010; 105:590-600.

11. Izumi Y, Oyama T, Ikeda E, Kawamura M, Kobayashi K. The acute effects of transthoracic cryoablation on normal lung evaluated in a porcine model. Ann Thorac Surg. 2005; 79:318-22; discussion 22.

12. Niu L, Xu K, Mu F. Cryosurgery for lung cancer. J Thorac Dis. 2012; 4:408-19.

13. Aerts JG, Hegmans JP. Tumor-specific cytotoxic T cells are crucial for efficacy of immunomodulatory antibodies in patients with lung cancer. Cancer Res. 2013; 73:2381-8.

14. Lv M, Xu Y, Tang R, Ren J, Shen S, Chen Y, Liu B, Hou Y, Wang T. miR141-CXCL1-CXCR2 signaling-induced Treg recruitment regulates metastases and survival of non-small cell lung cancer. Mol Cancer Ther. 2014; 13:3152-62.

15. Topalian SL, Hodi FS, Brahmer JR, Gettinger SN, Smith DC, McDermott DF, Powderly JD, Carvajal RD, Sosman JA, Atkins MB, Leming PD, Spigel DR, Antonia SJ, et al. Safety, activity, and immune correlates of anti-PD-1 antibody in cancer. N Engl J Med. 2012; 366:2443-54.

16. Thomas A, Hassan R. Immunotherapies for non-smallcell lung cancer and mesothelioma. Lancet Oncol. 2012; 13:e301-10.

17. Hasegawa T, Suzuki H, Yamaura T, Muto S, Okabe N, Osugi J, Hoshino M, Higuchi M, Ise K, Gotoh M. Prognostic value of peripheral and local forkhead box P3+ regulatory $\mathrm{T}$ cells in patients with non-small-cell lung cancer. Mol Clin Oncol. 2014; 2:685-94.

18. Hanahan D, Weinberg RA. Hallmarks of cancer: the next generation. Cell. 2011; 144:646-74.

19. Drake CG, Jaffee E, Pardoll DM. Mechanisms of immune evasion by tumors. Adv Immunol. 2006; 90:51-81.
20. Spellman A, Tang SC. Immunotherapy for breast cancer: past, present, and future. Cancer Metastasis Rev. 2016; 35:525-46.

21. Hadden JW. The immunology and immunotherapy of breast cancer: an update. Int J Immunopharmacol. 1999; 21:79-101.

22. Kubo M, Morisaki T, Kuroki H, Tasaki A, Yamanaka N, Matsumoto K, Nakamura K, Onishi H, Baba E, Katano M. Combination of adoptive immunotherapy with Herceptin for patients with HER2-expressing breast cancer. Anticancer Res. 2003; 23:4443-9.

23. Zhao Y, Hu J, Li R, Song J, Kang Y, Liu S, Zhang D. Enhanced NK cell adoptive antitumor effects against breast cancer in vitro via blockade of the transforming growth factor-beta signaling pathway. Onco Targets Ther. 2015; 8:1553-9.

24. Cheng M, Chen Y, Xiao W, Sun R, Tian Z. NK cell-based immunotherapy for malignant diseases. Cell Mol Immunol. 2013; 10:230-52.

25. Wang D, Zhang B, Gao H, Ding G, Wu Q, Zhang J, Liao L, Chen $\mathrm{H}$. Clinical research of genetically modified dendritic cells in combination with cytokine-induced killer cell treatment in advanced renal cancer. BMC Cancer. 2014; 14:251.

26. Li JJ, Gu MF, Pan K, Liu LZ, Zhang H, Shen WX, Xia JC. Autologous cytokine-induced killer cell transfusion in combination with gemcitabine plus cisplatin regimen chemotherapy for metastatic nasopharyngeal carcinoma. J Immunother. 2012; 35:189-95.

27. Pan K, Guan XX, Li YQ, Zhao JJ, Li JJ, Qiu HJ, Weng DS, Wang QJ, Liu Q, Huang LX, He J, Chen SP, Ke ML, et al. Clinical activity of adjuvant cytokine-induced killer cell immunotherapy in patients with post-mastectomy triplenegative breast cancer. Clin Cancer Res. 2014; 20:3003-11.

28. Pan K, Li YQ, Wang W, Xu L, Zhang YJ, Zheng HX, Zhao JJ, Qiu HJ, Weng DS, Li JJ, Wang QJ, Huang LX, He J, et al. The efficacy of cytokine-induced killer cell infusion as an adjuvant therapy for postoperative hepatocellular carcinoma patients. Ann Surg Oncol. 2013; 20:4305-11.

29. Ljunggren HG, Malmberg KJ. Prospects for the use of NK cells in immunotherapy of human cancer. Nat Rev Immunol. 2007; 7:329-39.

30. Yang L, Ren B, Li H, Yu J, Cao S, Hao X, Ren X. Enhanced antitumor effects of DC-activated CIKs to chemotherapy treatment in a single cohort of advanced non-small-cell lung cancer patients. Cancer Immunol Immunother. 2013; 62:65-73.

31. Zhong R, Han B, Zhong H. A prospective study of the efficacy of a combination of autologous dendritic cells, cytokine-induced killer cells, and chemotherapy in advanced non-small cell lung cancer patients. Tumour Biol. 2014; 35:987-94.

32. Li R, Wang C, Liu L, Du C, Cao S, Yu J, Wang SE, Hao X, Ren X, Li H. Autologous cytokine-induced killer cell immunotherapy in lung cancer: a phase II clinical study. Cancer Immunol Immunother. 2012; 61:2125-33. 
33. Zhong R, Teng J, Han B, Zhong H. Dendritic cells combining with cytokine-induced killer cells synergize chemotherapy in patients with late-stage non-small cell lung cancer. Cancer Immunol Immunother. 2011; 60:1497-502.

34. Han RX, Liu X, Pan P, Jia YJ, Yu JC. Effectiveness and safety of chemotherapy combined with dendritic cells cocultured with cytokine-induced killer cells in the treatment of advanced non-small-cell lung cancer: a systematic review and meta-analysis. PLoS One. 2014; 9:e108958.

35. Lin M, Liang S, Wang X, Liang Y, Zhang M, Chen J, Niu $\mathrm{L}, \mathrm{Xu} \mathrm{K}$. Short-term clinical efficacy of percutaneous irreversible electroporation combined with allogeneic natural killer cell for treating metastatic pancreatic cancer. Immunol Lett. 2017; 186:20-7.

36. Asimakopoulos G, Beeson J, Evans J, Maiwand MO. Cryosurgery for malignant endobronchial tumors: analysis of outcome. Chest. 2005; 127:2007-14.

37. Maiwand MO, Evans JM, Beeson JE. The application of cryosurgery in the treatment of lung cancer. Cryobiology. 2004; 48:55-61.

38. Yamauchi Y, Izumi Y, Yashiro H, Inoue M, Nakatsuka S, Kawamura M, Nomori H. Percutaneous cryoablation for pulmonary nodules in the residual lung after pneumonectomy: report of two cases. Chest. 2011; 140:1633-7.

39. Nagalla S, Chou JW, Willingham MC, Ruiz J, Vaughn JP, Dubey P, Lash TL, Hamilton-Dutoit SJ, Bergh J, Sotiriou C, Black MA, Miller LD. Interactions between immunity, proliferation and molecular subtype in breast cancer prognosis. Genome Biol. 2013; 14:R34.

40. Schmidt M, Bohm D, von Torne C, Steiner E, Puhl A, Pilch H, Lehr HA, Hengstler JG, Kolbl H, Gehrmann M. The humoral immune system has a key prognostic impact in node-negative breast cancer. Cancer Res. 2008; 68:5405-13.

41. Page DB, Naidoo J, McArthur HL. Emerging immunotherapy strategies in breast cancer. Immunotherapy. 2014; 6:195-209.

42. Ernst B, Anderson KS. Immunotherapy for the treatment of breast cancer. Curr Oncol Rep. 2015; 17:5.

43. Niu L, Chen J, He L, Liao M, Yuan Y, Zeng J, Li J, Zuo $\mathrm{J}, \mathrm{Xu} \mathrm{K}$. Combination treatment with comprehensive cryoablation and immunotherapy in metastatic pancreatic cancer. Pancreas. 2013; 42:1143-9.

44. Niu LZ, Li JL, Zeng JY, Mu F, Liao MT, Yao F, Li L, Liu $\mathrm{CY}$, Chen JB, Zuo JS, Xu KC. Combination treatment with comprehensive cryoablation and immunotherapy in metastatic hepatocellular cancer. World J Gastroenterol. 2013; 19:3473-80.

45. Lin M, Xu K, Liang S, Wang X, Liang Y, Zhang M, Chen J, Niu L. Prospective study of percutaneous cryoablation combined with allogenic NK cell immunotherapy for advanced renal cell cancer. Immunol Lett. 2017; 184:98-104.

46. Imai C, Iwamoto S, Campana D. Genetic modification of primary natural killer cells overcomes inhibitory signals and induces specific killing of leukemic cells. Blood. 2005; 106:376-83.

47. Zhang M, Daniel S, Huang Y, Chancey C, Huang Q, Lei YF, Grinev A, Mostowski H, Rios M, Dayton A. Anti-West Nile virus activity of in vitro expanded human primary natural killer cells. BMC Immunol. 2010; 11:3.

48. Witt CS, Christiansen FT. The relevance of natural killer cell human leucocyte antigen epitopes and killer cell immunoglobulin-like receptors in bone marrow transplantation. Vox Sang. 2006; 90:10-20.

49. Forte P, Baumann BC, Schneider MK, Seebach JD. HLACw4 expression on porcine endothelial cells reduces cytotoxicity and adhesion mediated by CD158a+ human NK cells. Xenotransplantation. 2009; 16:19-26.

50. Kunert K, Seiler M, Mashreghi MF, Klippert K, Schonemann C, Neumann K, Pratschke J, Reinke P, Volk HD, Kotsch K. KIR/HLA ligand incompatibility in kidney transplantation. Transplantation. 2007; 84:1527-33.

51. Moretta L, Moretta A. Killer immunoglobulin-like receptors. Curr Opin Immunol. 2004; 16:626-33.

52. Miller AB, Hoogstraten B, Staquet M, Winkler A. Reporting results of cancer treatment. Cancer. 1981; 47:207-14.

53. Goldberg SN, Grassi CJ, Cardella JF, Charboneau JW, Dodd GD 3rd, Dupuy DE, Gervais D, Gillams AR, Kane RA, Lee FT Jr, Livraghi T, McGahan J, Phillips DA, et al. Imageguided tumor ablation: standardization of terminology and reporting criteria. J Vasc Interv Radiol. 2005; 16:765-78. 